Acknowledgements: Thanks to S. Burdach and C. Goetz (both Laboratory for Functional Genomic and Transplantation Biology, Munich, Germany) for the exclusion of GM-CSF receptor mutations, and B. Trapnell and C. Stevens (Cincinnati Children's Hospital, Cincinnati, OH, USA) for measurement of anti-GM-CSF antibodies.

\section{REFERENCES}

1 Kitamura T, Uchida K, Tanaka N, et al. Serological diagnosis of idiopathic pulmonary alveolar proteinosis. Am J Respir Crit Care Med 2000; 162: 658-662.

2 Seymour JF, Presneill JJ. Pulmonary alveolar proteinosis: progress in the first 44 years. Am J Respir Crit Care Med 2002; 166: 215-235.

3 de Blic J. Pulmonary alveolar proteinosis in children. Paediatr Respir Rev 2004; 5: 316-322.
4 Dirksen U, Nishinakamura R, Groneck P, et al. Human pulmonary alveolar proteinosis associated with a defect in GM-CSF/IL-3/IL-5 receptor common $\beta$ chain expression. J Clin Invest 1997; 100: 2211-2217.

5 Beccaria M, Luisetti M, Rodi G, et al. Long-term durable benefit after whole lung lavage in pulmonary alveolar proteinosis. Eur Respir J 2004; 23: 526-531.

6 Seymour JF, Presneill JJ, Schoch OD, et al. Therapeutic efficacy of granulocyte-macrophage colony-stimulating factor in patients with idiopathic acquired alveolar proteinosis. Am J Respir Crit Care Med 2001; 163: 524-531.

7 Schoch O, Schanz U, Keller M, et al. BAL findings in a patient with pulmonary alveolar proteinosis successfully treated with GMCSF Thorax 2002; 57: 277-280.

8 Burgio GR, Monafo V. Infectious mononucleosis fifty years after the discovery of the Paul-Bunnell test. Infection 1983; 11: 1-5.

\title{
The fear of volcano: short-term health effects after Mount Etna's eruption in 2002
}

\section{To the Editors:}

The dramatic volcanic eruption in Iceland has recently brought the possible health effects of volcanic ashes to the general attention of the media. Lessons learnt from other episodes may be of interest and could guide future public health action.

During Autumn 2002, a large eruption of Mount Etna (Sicily, Italy) occurred. It persisted for 3 months, showing peaks of intense volcanic activity characterised by explosions, jets hundreds of metres high and seismic activity. Local winds carried the ash columns for kilometres, causing discomfort to the population of Catania (nearly 370,000 inhabitants) and other inhabited areas near the volcano. Repeated episodes of rainfall occurred after the eruption, reducing the phenomenon of ash resuspension. The population was alerted by a general alarm caused by national and local mass media. National and local authorities enacted measures aimed at preventing health effects: schools were closed; motor vehicle circulation was prohibited; protective eye masks were distributed; the elderly and individuals affected by chronic diseases of the respiratory system were suggested to limit their outdoor exposure and to reduce physical activity.

An epidemiologic study [1] on acute health effects on the nearby population was conducted. During the study period (106 days of observation in 2002; 59 days of eruption and 47 days of noneruption) unusually high levels $\left(>200 \mu \mathrm{g} \cdot \mathrm{m}^{-3}\right)$ of particulate matter with a $50 \%$ cut-off aerodynamic diameter $<10 \mu \mathrm{m}$ (PM10) were recorded (fig. 1). A 284\% increase in PM10 and 385\% increase in daily levels of sulfur dioxide $\left(\mathrm{SO}_{2}\right)$ were observed with respect to the previous year. No changes in nitrogen dioxide $\left(\mathrm{NO}_{2}\right)$ and carbon monoxide $(\mathrm{CO})$ were detected. Earthquakes [2] started 1 day before the onset of the eruption, with at least two earthquakes per day (above magnitude 3) during the first week of eruption. As shown in figure 1, the intensity of seismic activity was highly correlated with PM10 levels.
Both mortality and hospital admissions data were collected for all residents of the city during eruption and noneruption days in 2002, using the corresponding days in 2001 as a control. Relative risks (RR) of health events during the eruption with respect to the control period were computed both for mortality and for hospital admissions, shifted 1 day forward in order to take into account the day of the week effect. No changes in allcause (RR 0.98, 95\% CI 0.86-1.12) and cardiovascular (RR 1.09, $95 \%$ CI 0.90-1.32) mortality were observed, whereas a significant decrease in mortality for respiratory diseases during the eruption period was detected (RR 0.46, 95\% CI 0.46-0.82). Hospital admissions for cardiovascular diseases significantly increased (RR 1.18, 95\% CI 1.08-1.29), particularly for ischaemic heart diseases (RR 1.31, 95\% CI 1.10-1.56) and for cerebrovascular diseases (RR 1.24, 95\% CI 1.05-1.47), especially among people aged $>65$ yrs. Also notable, although not statistically significant, were admissions for eye disorders, two times higher during the eruption period than in the previous year. However, a decrease in hospitalisations for trauma was observed (RR 0.9, 95\% CI 0.8-1.0).

To evaluate the time relationship between daily PM10 levels and daily hospital admissions for cardiovascular diseases, a time-series analysis with Poisson regression was conducted (considering day of the week and holidays as confounders) and evaluating different time lags for PM10 concentrations $\leqslant 14$ days. No statistically significant association appeared, although the effect increased with time lags suggesting a delayed effect on cardiovascular health.

Studies on health hazards related to volcanoes [3] have reported cardiovascular and respiratory problems possibly related to particulate matter and/or to emitted gases. In fact, volcanic ash is generally composed of particles of fragmented volcanic rock, most of which are within the coarse fraction range $(2.5-10 \mu \mathrm{m})$. Other minor or temporary health effects 

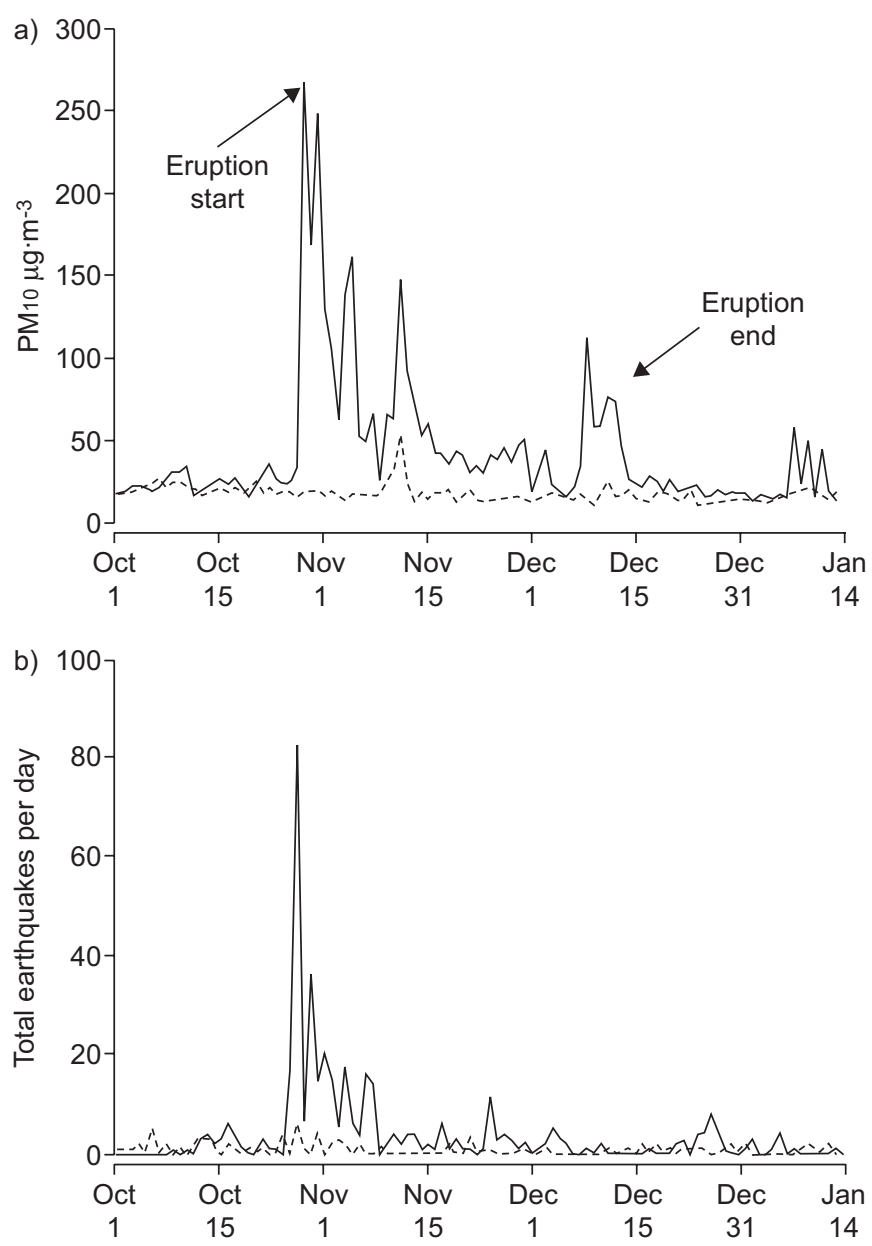

FIGURE 1. a) Daily mean particles with a 50\% cut-off aerodynamic diameter of $10 \mu \mathrm{m}$ (PM10) and b) seismic activity during the 2002 eruption of Mount Etna (Sicily, Italy). ——: 2002; -----: 2001 control.

have been reported in individuals who stay very close to craters for occupational reasons and in areas with ash contamination [4]. In our study, we observed an increase in $\mathrm{PM} 10$ and $\mathrm{SO}_{2}$ following the eruption, but not in $\mathrm{NO}_{2}$ or $\mathrm{CO}$. The relationship between daily PM10 level and cardiovascular admissions following Mount Etna's eruption shows that the effect was not immediate but, rather, delayed. Given the collinearity between the eruption and the earthquake, it is difficult to disentangle the responsible factor. However, previous studies strongly suggest that the stress was caused by the eruption and the frequent earthquakes experienced by residents could be responsible for our results. Reviews that have focused on the effects on cardiovascular diseases of unanticipated catastrophic natural event-related stress, such as earthquakes [5] or terrorist attacks [6], describe cardiac events as "indirect effects" of natural disasters, detectable in the long term $[7,8]$. Stress-related mortality from cardiovascular diseases was also reported among residents who experienced the Seveso dioxin accident [9] and in Los Angeles, CA (USA) during the 2 weeks before the turn of the millennium [10].

In our study, the preventive measures recommended to the population during the emergency period could explain the observed reduction of both the mortality for respiratory diseases and the decrease in hospital admissions for trauma: it is likely that people spent more time at home than during the control period, preventing car accidents and other minor trauma.

In conclusion, no increase in mortality was observed during Mount Etna's 2002 eruption. The temporary increase in cardiovascular morbidity, observed particularly among the elderly, may be a consequence of acute stress, as reported following other natural disasters. The decrease in mortality for respiratory diseases and the decrease in hospital admissions for trauma were likely a result of the precautionary measures taken during the emergency period. In any case, it is recommended that in future episodes, physicians closely monitor high-risk cardiac patients following natural disasters. Moreover, when planning public health measures during natural disasters, special attention should be given to risk communication and the consequences of general media alarm should not be neglected.

\section{Fano*, A. Cernigliaro", S. Scondotto", C.A. Perucci* and F. Forastiere*}

*Dept of Epidemiology, Lazio Regional Health Service, Rome, and "Dept of Epidemiology, Sicily Regional Health Authority, Palermo, Italy.

Correspondence: F. Forastiere, Dept of Epidemiology, Lazio Regional Health Service, Rome, Italy. E-mail: forastiere@asplazio.it

Statement of Interest: None declared.

Acknowledgements: The authors wish to thank S. D'Amico (National Institute of Geophysics and Volcanology of Catania, Catania, Italy) for his help in the selection of the meaningful information on earthquakes, and M. Becker for her editorial help.

\section{REFERENCES}

1 Fano V, Cernigliaro A, Scondotto S, et al. Health effects of environmental contamination due to volcanic ash of Mount Etna in autumn 2002. Epidemiol Prev 2005; 29: 180-187.

2 Italian National Institute of Geophysics and Vulcanology www. ct.ingv.it/index.php?option $=$ com_docman\&Itemid $=331 \& l a n g=$ it Date last accessed: August 19, 2010. Date last updated: August 17, 2010.

3 Hansell AL, Horwell CJ, Oppenheimer C. The health hazards of volcanoes and geothermal areas. Occup Environ Med 2006; 63: 149-156.

4 Cronin SJ, Sharp DS. Environmental impacts on health from continuous volcanic activity at Yasur (Tanna) and Ambrym, Vanuatu. Int J Environ Health Res 2002; 12: 109-123.

5 Kario K, McEwen BS, Pickering TG. Disasters and the heart: a review of the effects of earthquake-induced stress on cardiovascular disease. Hypertens Res 2003; 26: 355-367.

6 Qureshi EA, Merla V, Steinberg J, et al. Terrorism and the heart: implications for arrhythmogenesis and coronary artery disease. Card Electrophysiol Rev 2003; 7: 80-84.

7 Ogawa K, Tsuji I, Shiono K, et al. Increased acute myocardial infarction mortality following the 1995 Great Hanshin-Awaji earthquake in Japan. Int J Epidemiol 2000; 29: 449-455. 
8 Nakagawa I, Nakamura K, Oyama M, et al. Long-term effects of the Niigata-Chuetsu earthquake in Japan on acute myocardial infarction mortality: an analysis of death certificate data. Heart 2009; 95: 2009-2013.

9 Bertazzi PA, Bernucci I, Brambilla G, et al. The Seveso studies on early and long-term effects of dioxin exposure: a review. Environ Health Perspect 1998; 106: Suppl. 2, 625-633.
10 Poole WK, Chi JS, Walton JD, et al. Increased cardiovascular mortality associated with the turn of the millennium in Los Angeles County, California. J Epidemiol Community Health 2005; 59: 205-206.

\section{From Paul's predictions in the World Cup to the publication bias in genetic studies on complex traits}

\section{To the Editors:}

Recently, the octopus Paul has attracted much attention through the general media by his accurate predictions in the FIFA 2010 World Cup. During the World Cup, Paul predicted the outcomes of eight matches with $100 \%$ success. Assuming that Paul has $50 \%$ accurate choices as independent coin flips, the probability for a continual eight success prediction is 0.0039 . However, we may think that Octopus Paul is more likely to select the box with the German flag, for some reason. For example, when predicting the outcome of the Germany games Paul selected the box with the German flag five times out of seven, giving a percentage rating of $71.4 \%$ for selection of the German flag. Assuming Paul is more likely to select the German flag with a probability rate of 0.714 , the probability for the correct predictions Paul achieved in FIFA 2010 World Cup is $0.0076(0.714 \times 0.714 \times 0.714 \times 0.714 \times 0.714 \times$ $0.286 \times 0.286 \times 0.5)$. In the academic world, we usually select a probability boundary of 0.05 or 0.01 to reject the null hypothesis [1]. Therefore, we may conclude that Paul has the ability to correctly predict the outcomes of the world cup based on traditional statistical theory. Let us say the psychic octopus Paul has supernatural powers of predictions.

However, Paul's psychic powers became the focus of media attention just after the quarter-finals. At the group stage and the quarter-finals, Paul had predicted five accurate outcomes, with a probability value of 0.031 and 0.074 , respectively, for Paul's predictions similar to a coin flip or Paul's likelihood in selecting the German flag. It is obvious that there were many people around the world who were using animals or other ways to predict outcomes of the World Cup. Before the semifinals, we can assume there were more than 100 attempts (experiments) to guess the results of the World Cup. The pvalues of 0.031 or 0.074 should be adjusted for multiple tests. With the Bonferroni correction, the adjusted p-value will be close to 1 . Therefore, the significance of Paul's prediction before the semi-finals is unremarkable. After the quarter-finals, Paul predicted three accurate outcomes with p-values of 0.125 and 0.102 , respectively for a guess with a coin flip or Paul's likelihood of selecting the German flag. With the eyes of the whole world now watching Paul's predictions after the quarter-finals, we can assume that it was only one experiment, therefore, we do not need to adjust for multiple tests. However, the p-values of 0.125 or 0.102 are not significant in the view of statistics. Therefore, we conclude that the octopus, Paul, is a normal octopus without psychic powers of predictions.
Comparing the experience of Paul's prediction with the challenges of publication bias in genetic studies, we find they are extremely similar. This phenomenon may partly explain the inconsistencies in candidate gene association and genomewide association (GWA) studies on complex traits. Before the era of GWA studies, thousands of candidate gene association studies had been conducted. Due to publication bias and authors' desire and hidden intentions to publish positive results, many negative results were not submitted or accepted for publication. The published positive findings included significant false-positive results due to poorly accounting for multiple tests in general. Eventually, many of the candidate gene association studies on complex diseases (traits) were regarded as fruitless because many findings could not be consistently replicated in subsequent studies [2]. Now we are in the era of GWA studies. Hundreds of GWA studies have been published with many novel genes and new variants recently identified to be associated with disease phenotypes. However, among the reported genetic variants, how many are falsely positive? The published GWA studies usually included replications for their reported genetic variants in independent populations. However, are these replication attempts similar to Paul's prediction in the World Cup? How many GWA studies have been conducted and failed replication? As more and more GWA studies have been conducted, the issue of bias of publication will become more and more significant [3]. For example, GWA studies on asthma have shown inconsistency $[2,4,5]$. Will the GWA studies end up similar to candidate gene association studies? What can we do in the academic community to avoid the publication bias and include all negative findings?

Addressing this at the start, the National Institutes of Health has undertaken efforts to catalogue all published GWA studies. GWA studies are important and productive as they are identifying more and more genes related to complex diseases. However, it may be more important to amass all genetic information for all GWA investigations. It is timely to register all GWA studies regardless of their sample size and their positive or negative findings, and consequently have a collective dataset to hold all codes and genotype-phenotype association information for the human genome. This collective data will eventually help interpret our millions of genetic codes regarding our health. Although not a problem with advancements in computer storage technology, problems may arise in terms of ethics and practicality. However, if we still 